\title{
Endoscopic follow-up of rectum thermal damage concurred with the blast effect of gunshot injury
}

\author{
(1) Necattin Fırat ${ }^{1}$, (1) Ali Kağan Coşkun ${ }^{2}$, (1) Güvenç Cantilav ${ }^{3}$, (1) Ahmet Tarık Harmantepe ${ }^{1}$ \\ 1 Sakarya University Faculty of Medicine, Department of General Surgery, Sakarya, Turkey \\ 2University of Health Sciences Turkey, Gülhane Training and Research Hospital, Clinic of General Surgery, Ankara, Turkey \\ ${ }^{3}$ Antalya Elmali State Hospital, Clinic of General Surgery, Antalya, Turkey
}

\section{Date submitted: \\ 02.05.2020}

Date accepted:

13.07.2020

Online publication date:

15.06.2021

\section{Corresponding Author:}

Necattin Fırat, M.D., Sakarya

University Faculty of Medicine, Department of General Surgery,

Sakarya, Turkey

ORCID:

orcid.org/0000-0003-0684-8187

Keywords: Rectum injury, gunshot injury, blast effect

\begin{abstract}
Gunshot injuries can cause damage to the tissues due to mechanical or blast effects from bullets. In this type of injury in the pelvic area, a careful rectal examination is mandatory, and the patient may require a protective stoma in the presence of rectal injury. Rectal damage can be detected using laparoscopic and endoscopic techniques, resulting in lower morbidity and mortality. We here report a patient having rectum injury due to blast effect which resolved spontaneously without surgical intervention.
\end{abstract}

\section{Introduction}

Handguns or pistols are categorized as low-velocity firearms. Guns with muzzle velocities greater than $1000 \mathrm{~m} / \mathrm{sec}$ are called high-velocity firearms (1). High-velocity missiles can cause a temporary cavity. There is a significant risk of vascular capillary and injury, as well as local tissue loss. The so-called contusion and concussion zones of such a projectile may be as large as 2 $\mathrm{cm}$ and $7 \mathrm{~cm}$, respectively (2).

The greatest experience with the clinical process of traumatic rectum injuries has been derived from war-associated injuries. This type of injury usually progresses with high mortality, as it occurs with a gunshot and is accompanied by extensive tissue loss extending to complete rupture of the rectum (3). If the patient's condition is stable following abdominal injury, laparoscopy is an effective approach that can be used for both diagnostic purposes and treatment (4). However, when the injury is in the pelvic region, rectoscopy should also be added to laparoscopy in order to evaluate the retroperitoneal part of the rectum. If extraperitoneal rectal injury is observed, colonic diversion is the most appropriate approach for treatment (5). However, in the literature, there are some cases that have been successfully treated without extracolonic diversion in the extraperitoneal rectum injuries (6). The possibility of fullthickness rectum injury should not be ignored in the gunshot injuries of the pelvic region. Moreover, the possibility of perforation may also occur subsequently in the rectum due to the blast effect, which should be followed up at certain intervals with rectosigmoidoscopy. 


\section{Case Presentation}

A 20-year-old male soldier (body weight: $65 \mathrm{~kg}$, height: 170 $\mathrm{cm}$ ) was admitted to the Viranşehir State Hospital due to gun injury. His medical history was unremarkable for any chronic illness. Vital signs were stable (arterial blood pressure: 110/70 $\mathrm{mmHg}$, pulse: $65 / \mathrm{min}$ ). His physical examination revealed extensive tenderness and distension in the abdomen. Bullet inlet hole was in the posterior femoral head on the right and the bullet exit hole was in the posterior femoral head on the left. Urinary catheter could not be placed. Rectal examination showed gross blood. Laboratory tests showed leukocytosis hemogram [hemoglobin ( $\mathrm{Hb}): 14.8 \mathrm{~g} / \mathrm{dL}$, white blood cell (WBC): 23.3 K/UL, platelet (PLT): $187 \mathrm{~K} / \mathrm{UL}$ ] and normal blood chemistry. Abdominal tomography revealed fracture in the pelvic bone and leakage of contrast media into pelvis. There was no disruption in the integrity of the rectum (Figure 1,2).

The patient underwent diagnostic laparoscopy to explore urethral, rectal, and intra-abdominal injury. It was observed that the bladder was filled with urine and a cystostomy catheter was inserted into the bladder to purge urine. Except

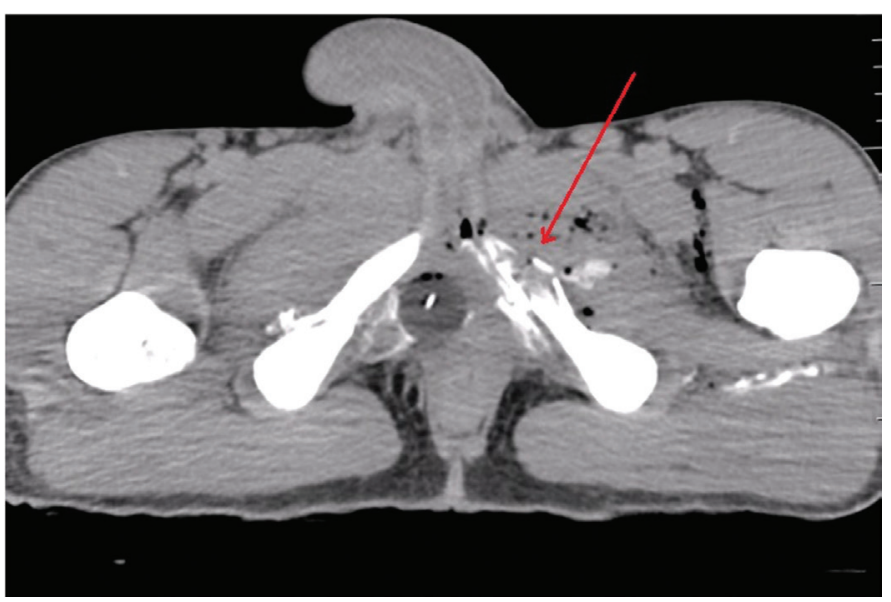

Figure 1. Fracture in the pelvic bone in abdominal computed tomography scanning

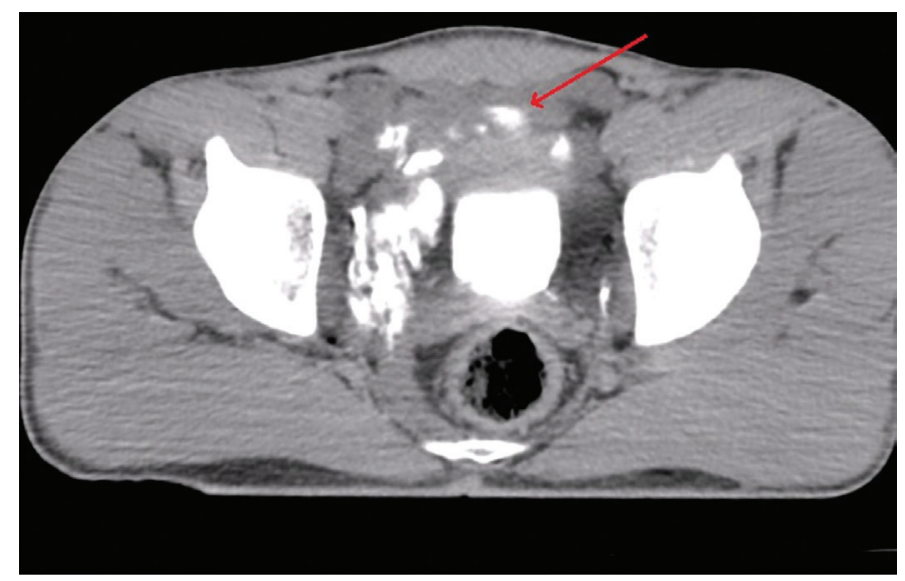

Figure 2. Leakage of contrast into pelvis in abdominal computed tomography scanning for the retroperitoneal hematoma, no pathology was observed in the pelvic region in the abdomen. Rectal examination was performed using rectoscopy which revealed a hyperemic eroded area with $2 \mathrm{~cm}$ in diameter due to the blast effect of the bullet. The lesion surrounded the lumen in 90 degrees $12 \mathrm{~cm}$ proximal to the anal canal.

The patient received antibiotic treatment with intravenous ceftriaxone and metronidazole. Vitals signs remained stable during follow-up, and blood tests at three-day follow-up was as follows: WBC: $11.1 \mathrm{~K} / \mathrm{UL}, \mathrm{Hb}: 12.2 \mathrm{~g} / \mathrm{dL}$, PLT: $148 \mathrm{~K} / \mathrm{UL}$, and C-reactive protein: $11.54 \mathrm{~g} / \mathrm{dL}$.

Control endoscopy was performed on postop 2. and 3. days (Figure 3,4 ). The lesion gradually shrank, and the patient was discharged with a cystostomy catheter.

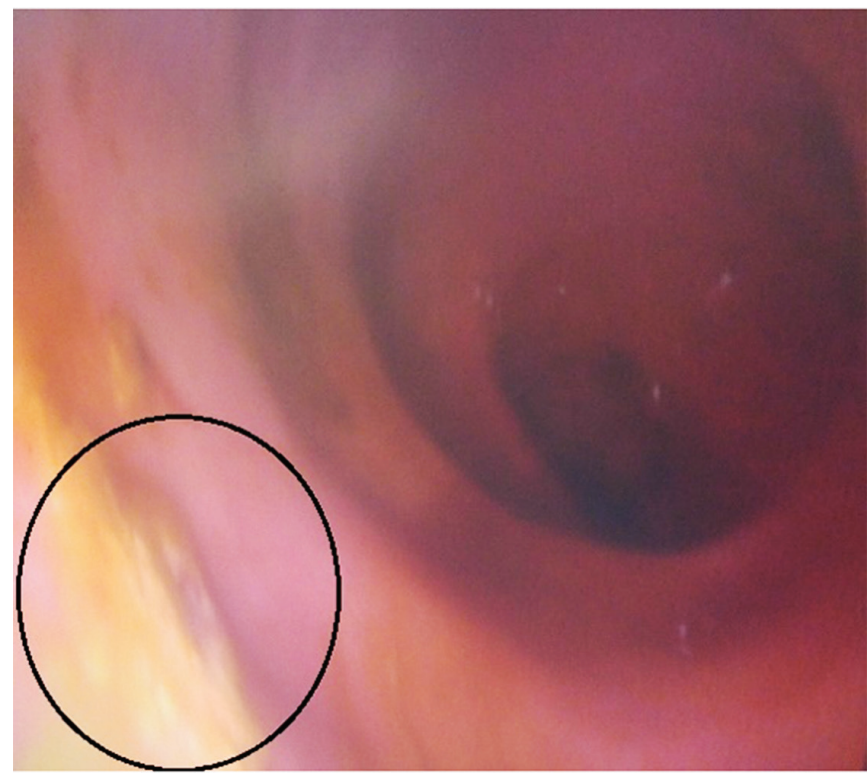

Figure 3. Rectum lesion, on postop $2^{\text {nd }}$ day

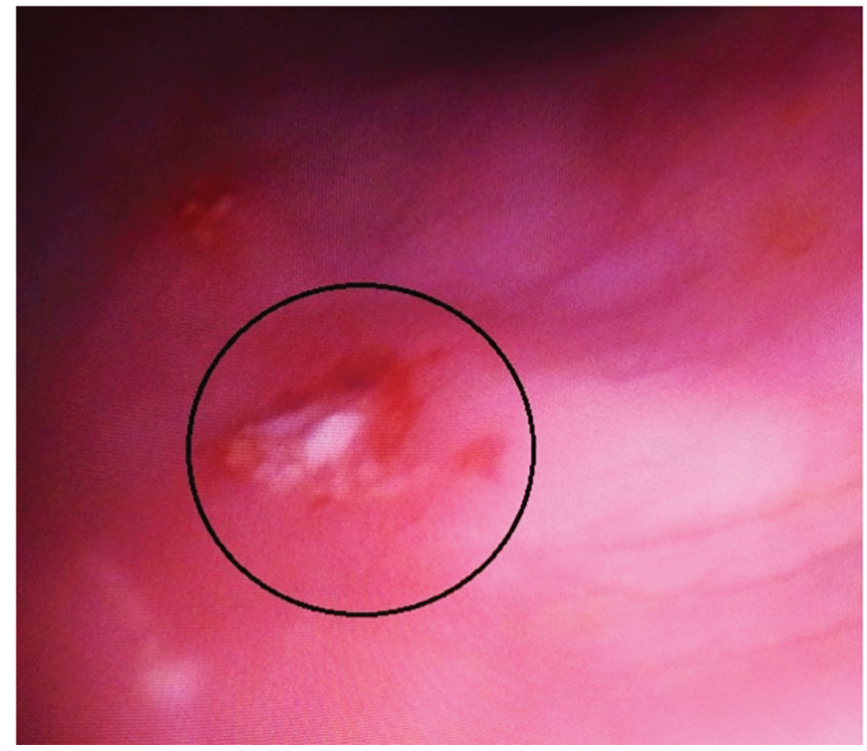

Figure 4. Rectum lesion, on postop $3^{\text {rd }}$ day 


\section{Discussion}

In gunshot injuries, morbidity and mortality vary according to the characteristics of the tissues. The bullet's mass and speed and the type of gun used are all involved in disrupting the tissue structures (7). With the blast effect in fire-arm injuries, the bullet causes damage to the region it enters and the surrounding tissues (8). If the patient has acute abdominal signs, the patient should be evaluated surgically. In studies conducted due to blunt abdominal trauma, laparoscopy reduces the number and complications of unnecessary laparotomies, provides faster recovery, and improves prognosis in surgical trauma patients (9). Gorgulu et al. (10) reported that the presence of colonic injury and the number of organs damaged (more than three) were the significant predictors of morbidity in penetrating abdominal gunshot wounds caused by high-velocity missiles and military rifle bullets. In our case, diagnostic laparoscopy was performed to determine whether the patient had an abdominal injury and whether the bullet caused damage to the intra-abdominal organs directly or blast effect. Anorectum and perineum injuries progress rapidly with high morbidity and mortality, especially in extraordinary conditions such as war and terrorism, due to possible additional injuries due to adjacent structures such as bladder, urinary tract, pelvis, and large vessel damage (11). Urethral injury should be suspected if a urinary catheter cannot be placed (11). The degree of soft tissue injury and contamination should be assessed in the first step in blunt or penetrating trauma events. Associated pelvic and perineal injuries should also be identified. Evaluation of sphincter integrity and mucosal/anodermal laceration is essential in the evaluation of these patients. Proctosigmoidoscopy should be performed to rule out associated rectal injury (12). Our patient underwent laparoscopy to assess whether the injury was associated with the abdomen, and glob vesicle was identified, and a cystostomy was performed. In addition, the erosional area detected 12 $\mathrm{cm}$ proximal to the rectum due to the blast effect was followed without diversion operation. Traumatic urethral injury is rare and can cause significant and long-term morbidity such as resistant urinary tract stenosis, incontinence, impotence, and infertility (13). If anastomotic urethroplasty cannot be performed due to the defect in the urethra under emergency conditions, a delayed repair can be performed in the urethra with a graft or flap at least three months after injury (14).

\section{Conclusion}

Even if the patient's condition is stable following a gun injury in the pelvis area, laparoscopy may be required to evaluate the potential injury to the intra-abdominal organs, and sigmoidoscopy may be required to evaluate the rectum. As in our case, rectum injury may occur due to blast effect but may recover without the need for a diversion surgery.

\section{Ethics}

Informed Consent: Written informed consent was obtained from the patient for publication of this case report and accompanying images.
Peer-review: Internally peer-reviewed.

\section{Authorship Contributions}

Surgical and Medical Practices: N.F., A.K.C., G.C., Concept: A.T.H., Design: A.T.H., Literature Search N.F., A.K.C., G.C., Writing: N.F., A.T.H.

Conflict of Interest: No conflict of interest was declared by the authors.

Financial Disclosure: The authors declared that this study received no financial support.

\section{References}

1. Cohen MA, Shakenovsky BN, Smith I. Low velocity handgun injuries of the maxillofacial region. J Maxillofac Surg. 1986;14:26-33.

2. Velitchkov NG, Losanoff JE, Kjossev KT, Katrov ET, Mironov $\mathrm{MB}$, Losanoff HE. Delayed small bowel injury as a result of penetrating extraperitoneal high-velocity ballistic trauma to the abdomen. J Trauma. 2000;48:169-170.

3. Altintoprak F. Penetrating rectum and bladder injury without perineal and sphincter damage after falling down from tree. Ege J Med. 2011;50:69-72.

4. Uranues S, Popa DE, Diaconescu B, Schrittwieser R. Laparoscopy in penetrating abdominal trauma. World J Surg. 2015;39:1381-1388.

5. Navsaria PH, Shaw JM, Zellweger R, Nicol AJ, Kahn D. Diagnostic laparoscopy and diverting sigmoid loop colostomy in the management of civilian extraperitoneal rectal gunshot injuries. Br J Surg. 2004;91:460-464.

6. Harry MF, Plummer JM, Stubbs M, Aitken R, Williams P. Nonoperative management of non-destructive extra-peritoneal rectal injury. West Indian Med J. 2011;60:344-345.

7. Hollerman JJ, Fackler ML, Coldwell DM, Ben-Menachem Y. Gunshot wounds: 1. Bullets, ballistics, and mechanisms of injury. Am J Roentgenol. 1990;155:685-690.

8. Bounovas A, Perente S, Laftsidis P, Polychronidis A, Simopoulos C. Perforation of the colon from the primary blast effect of an extraperitoneal shotgun injury: case report. Mil Med. 2007;172:327-328.

9. Zafar SN, Onwugbufor MT, Hughes K, et al. Laparoscopic surgery for trauma: The realm of therapeutic management. Am J Surg. 2015;209:627-632.

10. Gorgulu S, Gencosmanoglu R, Akaoglu C. Penetrating abdominal gunshot wounds caused by high-velocity missiles: a review of 51 military injuries managed at a level-3 trauma center. Int Surg. 2008;93:331-338.

11. Saydam M, Kozak O. Anorectum and perine ınjuries: morbidity source of war and terrorist Injuries. Med J Okmeydani Train Res Hosp. 2017;33:87-91.

12. Hellinger MD. Anal trauma and foreign bodies. Surg Clin North Am. 2002;82:1253-1260.

13. McGeady JB, Breyer BN. Current epidemiology of genitourinary trauma. Urol Clin North Am. 2013;40:323-334.

14. Bryk DJ, Zhao LC. Guideline of guidelines: A review of urological trauma guidelines. BJU Int. 2016;117:226-234. 